\title{
Forecasting and Evaluating Network Growth
}

\author{
David Levinson · Feng Xie · Norah M. Ocel
}

(C) Springer Science + Business Media, LLC 2009

\begin{abstract}
This research assesses the implications of existing trends on future network investment, comparing alternative scenarios concerning budgets and investment rules. The main scenarios compare "stated decision rules", processes encoded in flowcharts and weights developed from official documents or by discussion with agency staff, with "revealed decision rules", weights estimated statistically based on observed historical behavior. This research specifies the processes necessary to run the network forecasting models with various decision rules. We find that given the relatively small amount of funds available for network growth in a mature system, alternative decision rules make only small differences in overall system performance, though they direct investments to very different locations and affect the trip time and spatial accessibility in a significantly different way.
\end{abstract}

This material is based in part upon work supported by the US National Science Foundation under Grant No. 0236396. This research was also supported by the Minnesota Department of Transportation research project "Beyond Business as Usual: Ensuring the Network We Want is the Network We Get".

D. Levinson $(\varangle)$

Department of Civil Engineering, University of Minnesota, 500 Pillsbury Drive SE, Minneapolis, MN 55455, USA

e-mail: dlevinson@umn.edu

URL: nexus.umn.edu

F. Xie

Metropolitan Washington Council of Governments, 777 North Capitol Street, NE Suite 300, Washington, DC 20002, USA

e-mail: fxie@mwcog.org

\author{
N. M. Ocel \\ Loudoun County - Office of Transportation Services, 1 Harrison Street SE, \\ Leesburg, VA 20175, USA \\ e-mail: Norah.Ocel@loudoun.gov
}


Keywords Network growth • Decision-making • Forecasting • Evaluation • The Twin Cities

\section{Introduction}

A core problem of transportation planning is to identify infrastructure projects in which scarce resources are invested to maximize welfare. Some agencies proactively develop comprehensive transportation plans to guide these decisions and to provide certainty for other agents in the urban system, others make decisions by reacting to evolving market conditions and travel demands. Whether there is a comprehensive plan or not describing the "final" state of the network, the timing of future investment decisions is rarely specified beyond the current (typically 6-year) Capital Investment Program.

From the late 1950s through the 1980s, the Minnesota Department of Transportation $(\mathrm{Mn} / \mathrm{DOT})$ and other state transportation agencies focused primarily on the construction of the US Interstate Highway System. Mn/DOT relied on the nationally developed Interstate Plan and the locally developed Backbone System Plan to guide this effort (Minnesota Department of Transportation 2001). After completion of the Interstate, focus shifted within transportation agencies throughout the US from large-scale capital-intensive investments to the improved management of a mature infrastructure and an increased concern for the environment.

Policy plans in the 1970s and 1980s aimed to complete the metropolitan Interstate Highway System. Because the system was smaller and still new, the focus on management and preservation in those plans was not nearly as great as today. By the mid-1990s, the excess roadway capacity built in previous decades was largely utilized during peak periods, and problems with levels of congestion started to rise in the metropolitan area (Minnesota Department of Transportation 2001). Non-recurring congestion has increased as well, and it was found that $13 \%$ of traffic crashes were secondary crashes from incidentrelated congestion (Minnesota Department of Transportation 2005). Without any excess roadway capacity, safety issues rising in prominence, and new budget constraints, the need for better planning strategies arose.

Decision-making for investing in transport infrastructure is complex and political as well as technical, thereby holding intrinsic interests for researchers from various fields. Early exploration dates back to the 1960s, when transport geographers developed a series of models to replicate the structural transformation of transport networks (Garrison and Marble 1962; Taaffe et al. 1963; Kansky 1969). Heuristic and intuitive decision rules for network growth had to be introduced in these models, however, due to the limitation of modeling techniques and data availability at that time. In another strand of research, political economists have shown a long-lasting interest in the provision of public roads under different levels of jurisdictional controls (Oates 1972; Knight 2001; Besley and Coate 2003), although the temporal impact of the political decision- 
making processes in shaping transport networks has been little examined. In transportation planning, the prevalence of travel demand forecasting models (Sheffi 1985; de Dios Ortuzar and Willumsen 2001) since the 1950s made it possible to forecast travel demand on networks based on user equilibrium, thereby allowing traffic flows to be incorporated as an endogenous factor in forecasting network growth. Notably, network design problems (NDPs) develop a general bi-level framework in which the upper level represents the investment decision-making of transport planners to optimize social benefits within constraints based on the equilibrium flow pattern obtained from the lower level (Yang and Bell 1998). Although NDP provides an effective tool to predict changes to networks (Davis and Sanderson 2002), it fails to consider jurisdictional initiatives in decision-making processes.

In order to gain a better understanding of the jurisdictional decisionmaking processes, Montes de Oca and Levinson (2006) interviewed planners, engineers and staff from Mn/DOT, the Metropolitan Council, seven counties comprising the Twin Cities metropolitan region, and the City of Minneapolis, the largest city in the region. Official or stated decision rules of different jurisdictions were outlined, disclosing that road projects are prioritized for federal or local funding mainly based on their safety records, pavement conditions, level of service, and capacity. On the other hand, Levinson and Karamalaputi (2003a, b) adopted a statistical approach to examine the expansion and new construction on a road network. After estimating statistical models on two decades of data from the Twin Cities, they revealed that the likelihood for the expansion or new construction of a link is associated with a range of factors such as the present conditions of the network, traffic demand, project costs, and a budget constraint. Decision rules developed based on the statistical results are referred to as revealed rules in this study. As part of this research, the stated and revealed decision rules will be described later in detail.

This research investigates the timing and location of transportation investments in the seven-county Minneapolis-Saint Paul metropolitan area in Minnesota, and evaluates the effects of the investments. Stated and revealed decision rules of existing link expansion and new link construction developed in previous studies are included in a simulation environment to examine the growth of a highway network based on the present and historical conditions of the network, traffic demand, demographic characteristics, project costs and budget. The endogeneity of the network structure is a key contribution of this research over previous analyses that consider the topology of networks as exogenous.

In the next section, the overall model and research method is described. The following section overviews the simplified travel demand model that is constructed, which provides a research platform on which alternative scenarios may be tested. Then a set of investment models: budget, cost, and investment prioritization, are developed. The models are applied and alternative scenarios (forecasts) are produced and compared. The paper concludes with what was learned from undertaking this modeling exercise as well as recommendations for future analyses. 


\section{Modeling network growth}

As part of this research, an open-source Java-based model (main source code available at http://nexus.umn.edu/Software/SONG2_FINAL_ab.zip), System of Network Growth (SONG), extending earlier research (Yerra and Levinson 2005; Levinson and Yerra 2006), is developed. A flowchart illustrates the model framework in Fig. 1.

As can be seen, the program implements the growth of the Twin Cities road network as an iterative process at 5-year increments. Each iteration includes four steps: demographic information updating, travel demand models, investment models, and network updating. Provided that it takes around $30 \mathrm{~min}$ to run one iteration of the program (dual 2GHz PowerMac G5, 1GB

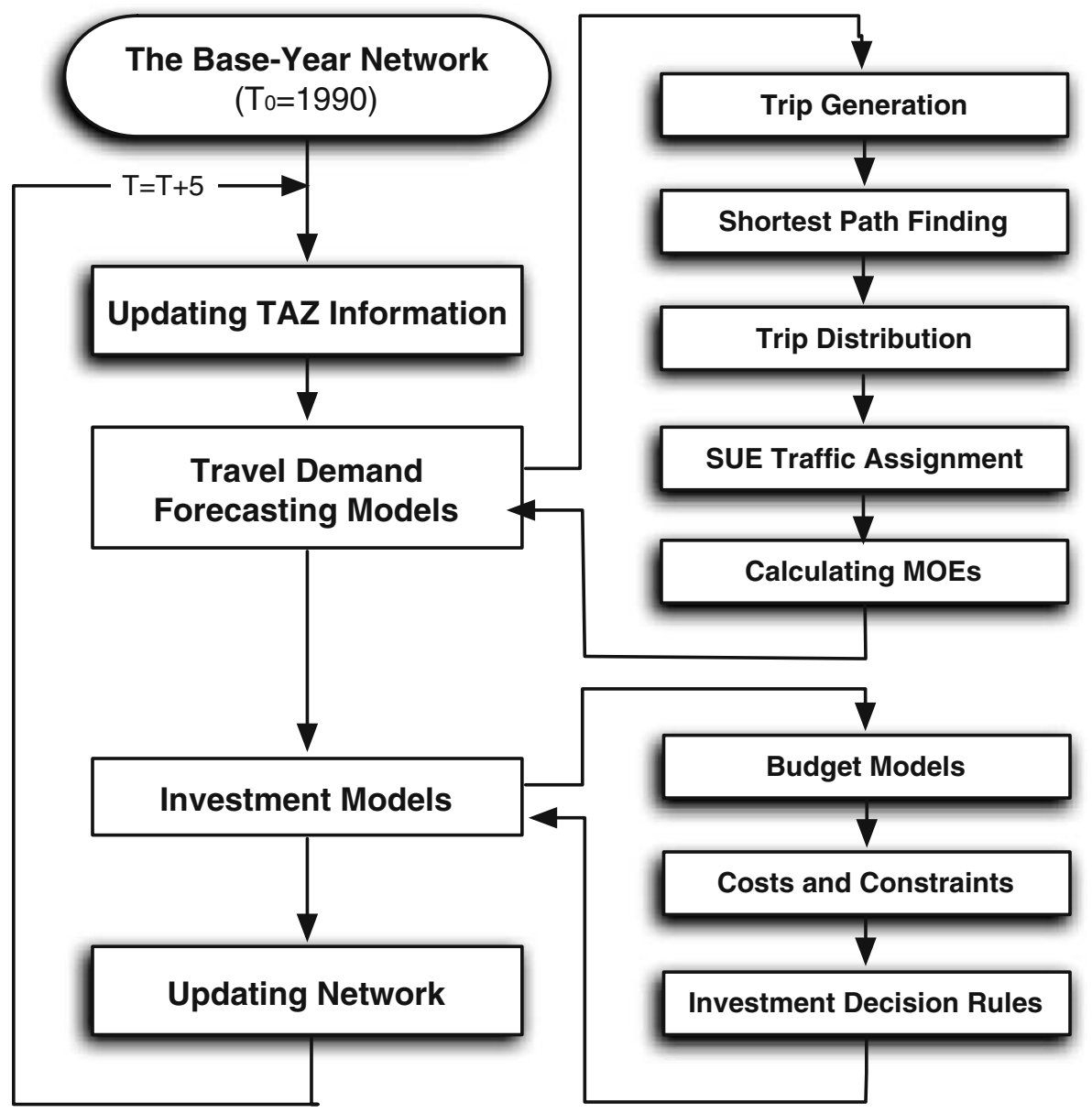

Fig. 1 Model framework of SONG 
DDR), a 5-year increment will substantially save the computational time as compared to smaller simulation periods (e.g. 1 year).

The first 15 years (1990-2005) can be thought of a warm-up phase for the calibration of the travel demand models. The network geometry, link attributes, and demographic information in the years of 1990, 1995, and 2000 are obtained from the Metropolitan Council's planning models as exogenous inputs to this program. ${ }^{1}$ The investment models are skipped during the calibration phase (so that the travel demand models can be calibrated) and the network is updated with exogenous link capacities at the end of each 5-year period. In calibration, model parameters were adjusted to minimize the difference between the predicted volumes of 2005 on major highways against the actual traffic counts obtained via loop detectors.

As the simulation continues with calibrated travel demand models, the forecasting phase starts from 2005 with the exogenous network topology, the estimated flow pattern (traffic across links) from the last simulation period (2000-2005), and the exogenous TAZ information provided by the Metropolitan Council. The Metropolitan Council also provides the forecasts of demographic information for the internal TAZs in the Twin Cities region every decade to 2030. The demographic forecasts every 5 years are then estimated by interpolation. For the 35 external stations, as traffic counts are available only for 1990 and 2000, it is assumed the volume of each external station will increase at a compound rate of $2 \%$ every year since 1990 , consistent with the average rate calculated from 1990 and 2000 actual traffic counts at external stations. At the beginning of each 5-year period from 2010 through 2030, the exogenous demographic forecasts are input to update the TAZ information, which is followed by the travel demand models, described in the next section, producing as outputs a network flow pattern and measures of effectiveness (MOE); these results are inputs to the investment process, which requires budget estimates (in part determined by vehicle distance traveled, as revenue depends on the gas tax) and cost estimates of potential projects, ranks potential discrete improvements (separately for the state and each county), and funds the highest ranked projects until the separate budgets are exhausted (once there is no budget available, there is a leftover deficit for the next time period); the projects upon implementation will change the network topology, which is updated endogenously before the time period is incremented.

\footnotetext{
${ }^{1}$ The original transportation planning network provided by the Metropolitan Council comprises 20,380 links, 7,723 nodes, 1,165 transportation analysis zones (TAZs) in the seven-county Metro Area, and 35 external stations. The planning network was modified to accommodate potential but unbuilt links, in particular what we call legacy links (projects that are in old transportation plans from the 1960s but that have not yet been constructed). The general idea is that if a legacy link intersects an existing link, there is a creation of a new node and the old link is divided into two different links. In the revised network representation there are 20,398 links and 7,733 nodes.
} 


\section{Travel demand models}

The travel demand models include three component models of trip generation, doubly constrained trip distribution, and Stochastic User Equilibrium (SUE) traffic assignment, which simplify the traditional travel demand forecasting process by dropping mode choice, and instead directly estimate vehicle trips. We also do not model freight trips directly, and instead inflate passenger car trips to account for missing trucks. We are modeling traffic in the AM Peak Hour (the average hour between 6:00 am and 9:00 am), calibrating against that, and then using peak hour to daily expansion factors where required to obtain Annual Average Daily Traffic or AADT (which is required in some of the investment models). Peak hour volumes rather than AADT are used for calibration because peak hour volumes are accurately measured by detectors on a continuous basis and well maintained by Mn/DOT's Traffic Management Center, while many AADT measures are just estimates of actual traffic volumes. The calibration managed to reduce the average error between predicted and observed peak hour volumes on all major highways in the Twin Cities region to $0.78 \%$, and the root mean square error (RMSE) to $30.0 \%$.

The models essentially simplify the transport planning models developed by the Metropolitan Council. While the Metropolitan Council models capture more details about certain aspects of travel and can be more accurate, it is at the cost of requiring more data and resources. This research examines the investment on road networks and its effects by modeling multiple years of network growth, which is computationally more intensive. To do that in reasonable time, some details in travel demand forecasting are sacrificed.

It is worth noting that the computation for the initial year (1990) is iterated (using method of successive averages) between inputs to trip distribution and outputs from route assignment to obtain an equilibrium. Trip distribution requires peak hour interzonal travel costs $\left(C_{i j}\right)$ as input, which are the output of traffic assignment. This is particularly important for the base year where we do not have a congested seed travel time matrix a priori. In this research, the initial network flow pattern is estimated by running the program beginning with free flow travel times on the 1990 network geometry, and iterating between trip distribution and route assignment (using outputs of assignment as inputs to trip distribution) until the maximum difference in travel time between two successive iterations is $0.1 \mathrm{~h}$ for any OD pair, and the average difference is $.0025 \mathrm{~h}$ for all OD pairs. Once these criteria are met, the resultant flow pattern is used as exogenous input for the base year network and no distribution and assignment iteration is undertaken during the subsequent simulation periods.

As the focus of this research is the investment process of network growth, the detailed description of the component models is skipped. More details on model setup and calibration can be found in Levinson et al. (2006). The global parameters with specified values for the travel demand models are summarized in Table 1. 
Table 1 Estimated models of trip generation and trip attraction

\begin{tabular}{lll}
\hline Parameter & Value & Description \\
\hline$\alpha, \beta$ & $0.15,4.0$ & $\begin{array}{l}\text { Coefficients in the BPR function (Bureau of Public Roads 1964) } \\
\text { Scaling factor that converts daily traffic to peak hour traffic, } \\
\text { adopted from Suwansirikul et al. (1987) } \\
\text { Calibrated percentage increase of initial highway capacity, based on } \\
\text { the assumption that the real capacity on highways is } \\
\text { underestimated by Metropolitan Council. }\end{array}$ \\
$\epsilon$ & $20 \%$ & $\begin{array}{l}\text { Calibrated travel cost friction factor in gravity-based trip distribution. } \\
\text { Scaling factor in stochastic route choice, adopted from Davis and } \\
\text { Sanderson (2002). A value of 0.2 indicates that if one route } \\
\text { is 5 min faster than the other, 3 out of 4 travelers will choose } \\
\text { the faster route. }\end{array}$ \\
\hline
\end{tabular}

\section{Investment models}

The investment models predict budgets, estimate costs and constraints of potential road projects, and apply investment decision rules. This process outputs changes to the network in terms of link addition and link capacity expansion. The implementation of the investment models in SONG is illustrated in Fig. 2 and the component models are discussed below.

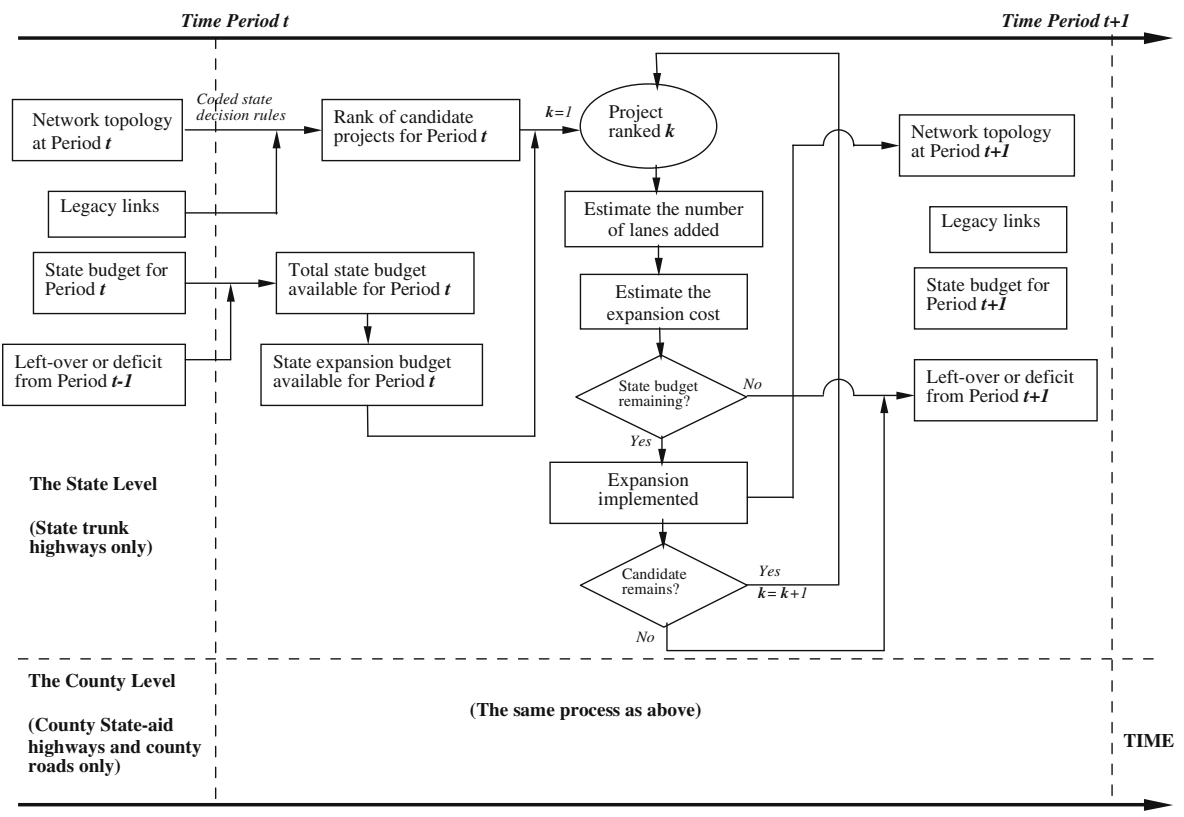

Fig. 2 The flowchart of the investment process 


\subsection{Budget models}

In order to predict how much construction will occur in a given year, there is a need to know the available transportation budget.

Links that belong to the state (including Interstates, US Highways, and state highways) are ranked by state rules and are constrained by state budgets. Links that are under county jurisdiction are ranked by the respective county level decision rules. These links include County State Aid Highways (CSAH) and county roads. Other links that are not owned by these jurisdictions (such as park roads or roads owned by cities or townships) are not modeled in this investment model, and are assumed static. For this reason there is a need to estimate two different budget models for the state and for counties.

Once all links have been scored under each jurisdiction's decision rules, links are sorted and the budget is allocated to the links with the highest scores. A general assumption is that jurisdictions will spend all their budgets in that time period. If budgets are short on building one last project, jurisdictions will borrow from the next time period (decreasing available revenue in that subsequent period).

In order to predict the budget more accurately, the vehicle kilometers of travel (VKT) numbers predicted by this program are adjusted to published ones obtained through public agencies based on measured and estimated traffic counts. This is because the planning network used in this research does not include every link belonging to a particular jurisdiction, meaning that VKT produced by this model may underestimate the real counts.

The State budget model is estimated by regressing expenditures on state managed routes (Interstate, U.S. and Minnesota Trunk Highways) made by $\mathrm{Mn} / \mathrm{DOT}$. No distinction is made between the sources of funding. The regression model takes into consideration data available for the years from 2000 to 2004. A variety of regression models were tested, they included population, annual growth, residential density, network size, number of crashes, pavement conditions, households, income per household, car ownership, year, households per population as predicting variables. However, the simplest model, determined only by VKT (vehicle km traveled only on state managed routes), proved to have the greatest explanatory power. As displayed in Table 2, this model produced an r-squared of 0.82 . Primarily through gas taxes, each vehicle $\mathrm{km}$ traveled adds approximately 0.6 cents to the state road budget. There were a total of 35 observations (seven counties by 5 years each).

The county budget model is estimated by regressing the expenditures made by the counties on County State Aid Highways and county roads. A number of variables were tested, including population, annual growth, residential density, network size, number of crashes, pavement conditions, households, income per household, car ownership, year, households per population, and shortest distance from the zone's centroid to either Minneapolis or St. Paul downtown. The model was estimated based on 28 observations for the years 1990, 1995, 2000 and 2003 (seven counties by 4 years each) and the final model that provided the highest $\mathrm{r}$ squared (0.92) with significant variables is also presented 
Table 2 Highway budget models

\begin{tabular}{lllllr}
\hline & \multicolumn{2}{l}{ State of Minnesota } & & Counties \\
\cline { 2 - 3 } & Coef. & $\mathrm{t}$ stat & & Coef. & $\mathrm{t}$ stat \\
\hline Intercept & 22146206 & 5.55 & & 10289970 & 4.04 \\
Households & & & -78 & -1.98 \\
VKT & 0.006 & 12.39 & & 0.0047 & 4.16 \\
Dummy for 1990 & & & -11552700 & -3.64 \\
Dummy for 1995 & & & -5900211 & -2.03 \\
Dummy for 2000 & & & -3491842 & -1.32 \\
Adjusted R square & 0.82 & & 0.9 & \\
$\mathrm{~N}$ & 35 & & 28 & \\
\hline
\end{tabular}

in Table 2. Note that the predictive value of the model may be hampered by the yearly dummies; due to the limited number of records available, however, we did not test the stability of the model structure over time. Instead it is assumed the estimated spending pattern is stable in the forecast years.

Transportation budgets need to be separated into maintenance and construction budgets. Based on the current spending pattern in the Twin Cities Metropolitan Area as noted in Minnesota Department of Transportation (2001), this research assumes $21 \%$ of the total budget is spent on construction and $79 \%$ is spent on maintenance. Sensitivity analyses are also undertaken (later in Scenario 5) to test the effects of varying the available construction budget. The construction budget further allocates funds between capacity expansion of existing facilities (which largely serve existing needs) and the construction of new facilities (which open up new areas to development).

A major modeling issue is the allocation of the $21 \%$ of budget devoted to network construction between expanding existing links and building new links. The number of existing links is known, as are their attributes (congestion level, crash rate, etc.); possible future links (new construction) on the other hand comprise a much more challenging problem.

Only a few legacy links in this analysis have already been clearly laid out. These legacy links have appeared on state maps and plans since at least the 1960s, and have been political promises to the affected areas that a new road would eventually be built. In the Twin Cities, state-level legacy links include the extensions of freeways Highway 610 and Highway 212. Figure 3 shows all of the links that were proposed in the 1960 Metropolitan Transportation Study that were (A) Proposed and built, (B) Proposed and not built (marked in red), and $(\mathrm{C})$ Not proposed at the time, but built (Links that were not proposed and not built cannot be easily mapped).

For lower levels of government in the Twin Cities region, such long-term plans are uncommon. Yet from time to time, new links are constructed. Levinson and Karamalaputi (2003b) developed a series of rules that were used to identify potential links depending on the traffic at the nodes (which were assumed to already exist), length (not too short, not too long), and local characteristics (not crossing more important links). That set of rules produced over ten thousand possible new links for the Twin Cities network, of which a few dozen were built in the past 20 years. 


\section{Legacy Links in the Twin Cities}

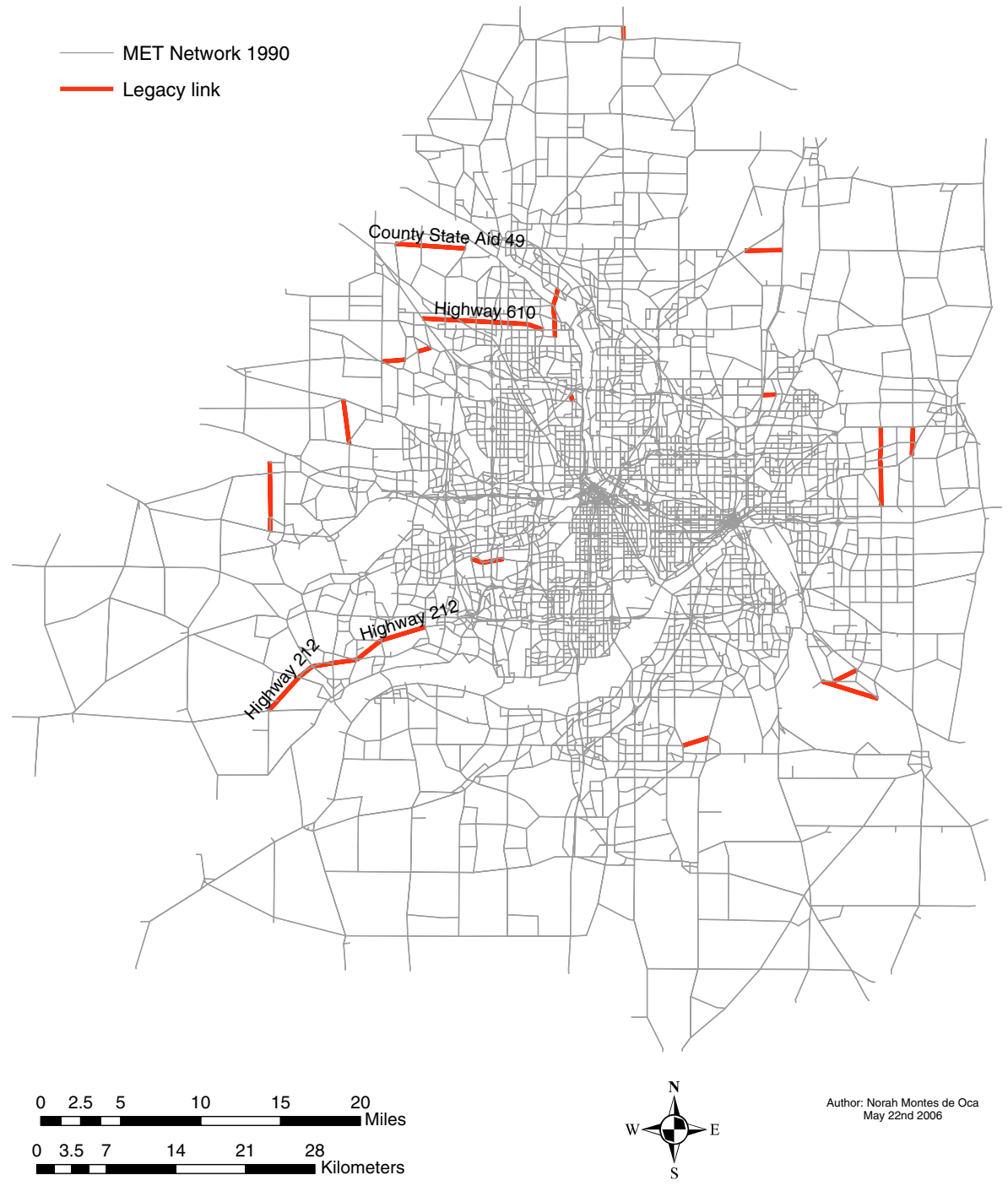

Fig. 3 The map of legacy links in the Twin Cities

Since the rules for prioritizing expansions of existing links and construction of new links are different (which will be explained in Section 4.3), it is very difficult to compare them on a standard metric. One can compare two expansion projects or two construction projects, but there is no easy translation between them. Thus it is easier to establish separate budgets for link expansion and new link construction, rather than making them compete directly for resources. From 1978 to 2004, in the Twin Cities Metropolitan Area, there 
were 945 lane $\mathrm{km}$ added to the transportation system at the level of principal arterial or higher. Among those, 821 lane $\mathrm{km}$ were new construction and the remainder were expansions of existing facilities. During those 26 years $85 \%$ of the dollars spent went to new link construction while $15 \%$ was allocated to link expansion and reconstruction. The average cost for new construction was $\$ 1,495,000$ per lane $\mathrm{km}$ while for expansion it was $\$ 752,000$ per lane $\mathrm{km}$, which represents a $50 \%$ difference. As the network matures, this ratio is expected to change. For modeling purposes, we assume forecast expenditures will be split 50/50 between expansion and new construction (a split of 75/25 is also tested in an alternative scenario for comparison), until the number of new construction projects is exhausted, at which time, the excess new construction revenue will be reallocated to expansion.

\subsection{Costs and constraints}

This research adopts a model of facility construction cost estimated by Levinson and Karamalaputi (2003a). This model takes into consideration facility size, new construction (vs. expansion), road type, as well as the distance from the nearest downtown. This model was estimated on facilities that were actually built. It is important to mention that the cost model will underestimate costs for roads that were not built, for which high cost may have been a discouraging factor. One way to account for this is to better consider constraints on investment as additional costs. Alternatively, constraints can reduce the points allocated to potential projects in the decision rules (the approach we take). Two major constraints are available right-of-way (ROW) and environmental factors.

Interstates, highways, county roads and streets often require taking real property for ROW. This aspect needs to be addressed when analyzing results of the expansion/new construction of the possible transportation network additions. While in some areas there is a possibility of obtaining land on the side of existing roads to expand them if needed at a reasonable price, in many urban areas this is infeasible because of existing structures. The available ROW in the heart of urban communities is a constraint.

This research tried to consider the ROW available on both sides of the roads that are prospects for expansion using Geographic Information System (GIS) technologies. But there was no data available for this specific type of analysis. A GIS land use file including a category named "right of way" was available, but for this analysis more specific data was required (i.e. spatial location of each building within the parcel data, as well as specific location of highways within the ROW, lane width, sidewalk width, and so on).

There are significant terrestrial and wetland ecological areas in the sevencounty metropolitan area to take into consideration for the predicted expansion of the transportation network. The areas are classified by Minnesota Department of Natural Resources (2003) as Outstanding, High, Moderate and Non-classified based on the importance of ecological attributes like size, shape, cover type diversity and adjacent land use. These areas include individual 
forests, grasslands and wetlands. Potential links that traverse these ecologically sensitive areas, as well as bodies of water like rivers and/or lakes and over parks as well, are marked as constrained.

The investment models with stated decision rules (discussed below) rank road projects by their scores that indicate their potential benefits, not costs. Costs are used to allocate available funds. Thus, when a link predicted for expansion and/construction is constrained by any of these areas, instead of allocating points, points will be taken away. Based on a scale 0 to 100, it is assumed constraints will cause 90 points to be de-allocated from that link, which in an era of constrained budgets, should ensure it does not get funded.

\subsection{Decision rules}

Two classes of decision rules are used in the analysis: stated rules, garnered from interviews (Montes de Oca and Levinson 2006), and revealed rules, determined by statistical analysis (Levinson and Karamalaputi 2003a, b) and briefly described below.

For the stated rules, in some cases they are relatively clearly outlined in public documents, while in other cases, those processes were much more informal, and required judgment to ascertain. In order to uncover formal and informal procedures, performance measures, and decision rules that have been actually used, interviews were undertaken with Mn/DOT, the Metropolitan Council, County, and City of Minneapolis planners, engineers and staff involved in the decision-making process on future network growth. These interviews were conducted in groups as well as individually, in which the following free-form questions were asked:

1. What is the procedure for a project to be approved for construction?

2. What are the most important policies to look at when making decisions about a project for the network growth?

3. What are the main criteria to choose between different projects?

4. What performance measures are considered important when selecting a project?

5. Have there been changes in the criteria used today as those that were used 20 years ago about network development?

6. Are there any informal procedures for the decision-making process?

7. How important of a role do politics play in the decision-making process?

From these interviews a series of flowcharts were developed and encoded into the computer model. The decision flowcharts are made operational as If-Then rules. The If-Then rules implement a point allocation that covers the decision rules that are considered by each government jurisdiction in a numerical ranking format.

These points are assigned based on the characteristics of the roadways located in each county. Every county has its own decision rules. Counties that did not provide decision rules were assigned decision rules of a similar adjoining 
county. For decision rules that are based on subjective criteria (e.g. public support for a specific project), there was no numerical way to allocate points, therefore these types of decision rules were not taken into consideration for any of the calculations. The four main factors that were common between flowcharts were Safety, Pavement Conditions, Level of Service, and Capacity. Points need to be continuous in order to ensure that each project obtains a unique score from a jurisdiction, so discrete points associated with ranges were converted to continuums.

Taking Hennepin County as an example, the Normalized Scoring System of the county evaluates the funding needs of a road project from three aspects:

- Safety. Roads belonging to this county are categorized into groups according to road types (urban or rural, divided or undivided) and number of lanes. The ratio of the crash rate on a road to the average crash rate of its group is calculated based on which specific points are added to this road.

- Pavement quality. Pavement Quality Index (PQI) of each road is calculated and points are allocated to a road according to its normalized PQI.

- Level Of Service (LOS). The ratio of Annual Average Daily Traffic (AADT) to current capacity is calculated as a LOS indicator for each road and points are allocated according to normalized LOSs.

The decision rules developed by Scott County, on the other hand, are less structured, which consider only two criteria: if road location is among the top 200 high crash list, certain points are allocated to the road; if the ADT of a road is above a threshold, certain points are allocated; otherwise no points will be allocated. Note that crashes on roads are not endogenized in this program and historical crash records rather than predicted ones are used in applying the related decision rules in the forecasting process. Details on the flow charts, IfThen rules, and point allocation criteria are available in Levinson et al. (2006).

As the stated rules are primarily concerned with expansion projects, the revealed decision rules developed by Levinson and Karamalaputi (2003a, b) are also introduced, which apply the statistical models estimated respectively for expansion and for new construction. The expansion of facilities on the existing network by one or two lanes is estimated using a discrete choice model with independent variables describing conditions of the network, traffic demand, other demographic characteristics, estimated project costs, and a budget constraint. The likelihood of expansion of a link depends also on its upstream and downstream neighbors, as well as on the state of parallel links. The model suggests that high capacity links are more likely to be expanded. New highway construction was estimated in a discrete choice model to be based on the status of the network, project costs, the conditions on upstream and downstream and parallel links, and budget constraints. An algorithm was developed to generate a large choice set of potential new links, to which the discrete choice model was applied. New links providing greater potential access are more likely to be constructed. 


\section{Scenarios}

A range of seven scenarios has been constructed to examine how the timing and location of road expansion and new construction predicted by the simulation program SONG would be affected by varying:

- Decision rules for expansion

- Decision rules for new construction

- Total budget

- Budget split between expansion and new construction

- Choice set of potential new links.

The scenarios are summarized in Table 3.

Scenario 1 presents the baseline scenario, consistent with the assumptions described in last section. In Scenario 2, the most structured decision rules (those from Hennepin County) are applied for link expansion to every county; while in Scenario 3, the least structured decision rules (those of Scott County) are applied for link expansion. For new construction, the revealed decision rules are used to prioritize links in all cases.

In all the scenarios, the total budget available for road investment is estimated using the baseline budget model described in the last section, except in Scenario 4, where the budget alternatives are tested. Scenarios 4a$4 \mathrm{e}$ respectively assume the construction budget allocated to each jurisdiction for each time interval is increased by $100 \%, 200 \%$ and $400 \%$, and reduced by $10 \%$ and $25 \%$ (which is essentially equivalent to varying the budget split between construction and preservation). The construction budget is split evenly between expansion of existing links and new construction, except in Scenario 5, where three-fourths of all dollars are allocated to new construction. When opportunities for new links are exhausted (all of the legacy links have been built), that budget is reallocated to link expansion.

In contrast to Scenarios 1-5 that adopt stated decision rules for expansion, Scenarios 6 and 7 adopt revealed rules instead. While all of the scenarios take existing links as a baseline and consider them for expansion, the scenarios

Table 3 Scenario descriptions

\begin{tabular}{llllll}
\hline & $\begin{array}{l}\text { Expansion decision } \\
\text { rules }\end{array}$ & $\begin{array}{l}\text { New construction } \\
\text { decision rules }\end{array}$ & $\begin{array}{l}\text { Total } \\
\text { budget }\end{array}$ & $\begin{array}{l}\text { Expansion } \\
\text { budget split }\end{array}$ & $\begin{array}{l}\text { New link } \\
\text { choice set }\end{array}$ \\
\hline 1 & Stated & Revealed & Standard & $50 / 50$ & Legacy \\
2 & Most structured & Revealed & Standard & $50 / 50$ & Legacy \\
3 & Least structured & Revealed & Standard & $50 / 50$ & Legacy \\
4 & Stated & Revealed & $4 \mathrm{a} 100 \%+$ & $50 / 50$ & Legacy \\
& & $4 \mathrm{~b} 200 \%+$ & & \\
& & $4 \mathrm{c} 400 \%+$ & & \\
& & & $4 \mathrm{~d} 10 \%-$ & & Legacy \\
5 & Stated & & $4 \mathrm{e} 25 \%-$ & & Legacy \\
6 & Revealed & Standard & $25 / 75$ & All potential \\
7 & Revealed & Revealed & Standard & $50 / 50$ & \\
\hline
\end{tabular}


differ in what links to consider for new construction. Consistent with the first five scenarios, Scenario 6 uses only legacy links as links that are eligible for new construction, while Scenario 7 adds a set of potential links that have not been pre-specified on historical maps due to the relative scarcity of legacy links that are available for investment.

The additional set of potential new links in Scenario 7 is generated using the Levinson and Karamalaputi (2003b) model. It begins by identifying all existing node pairs that meet a specific set of criteria. The type of potential link is identified based on the highest-level link coming into each of the nodes. If a node is attached to a freeway link, a potential new link will be part of the freeway link level. The potential links are constrained: new streets cannot cross existing higher-level roads (such as highways or freeways), but freeways and highways can cross streets. Every combination of two existing nodes is considered and the possibility of establishing a link between them is evaluated. The candidate link should be longer than $200 \mathrm{~m}$ and shorter than $3200 \mathrm{~m}$ in the Twin Cities area. Consequently, a total of 14,826 potential links are identified in the Twin Cities Metropolitan Area, though only a few of them are constructed each year according to the traffic condition and budget constraints.

Potential links in the additional set of candidates that would cross parks, water areas and other ecologically sensitive areas are excluded from the choice set (and were not constructed in the model). However, legacy links with such constraints are constructed with a penalty in length since the link has to detour in order to get built. This penalty length was assumed to be 1.4 times the airline length and consequently makes it more expensive to construct.

For all scenarios, once a link has been expanded, it is no longer taken into consideration for further expansion. For new construction, state roads are assumed to be two lanes in each direction, whereas county roads are only one lane in each direction. Newly constructed roads are eligible for expansion if necessary in the future. Additionally, it is assumed that all expansion and construction decisions for links are symmetric, which is typical in the Twin Cities Metropolitan Area. This means that in case of expansion and new construction an equal number of lanes will be added in both the $i j$ and $j i$ directions. However for one-way streets, only one-way expansion is considered, which allows asymmetric developments.

\section{Results}

Simulation results are summarized in Figs. 4-10. To save space, only Scenarios 1,6 , and 7 are elaborated. For a full description of the seven scenarios and their respective results, refer to Montes de Oca (2006). Note in the figures that each simulation period is labeled by the first year in this period (thus 2005 represents the period from 2005-2010, 2010 represents the period from 20102015, and so on).

Figures 4 and 5 compare the scenarios based on overall results with respective regard to new construction and expansion for the state. New construction 


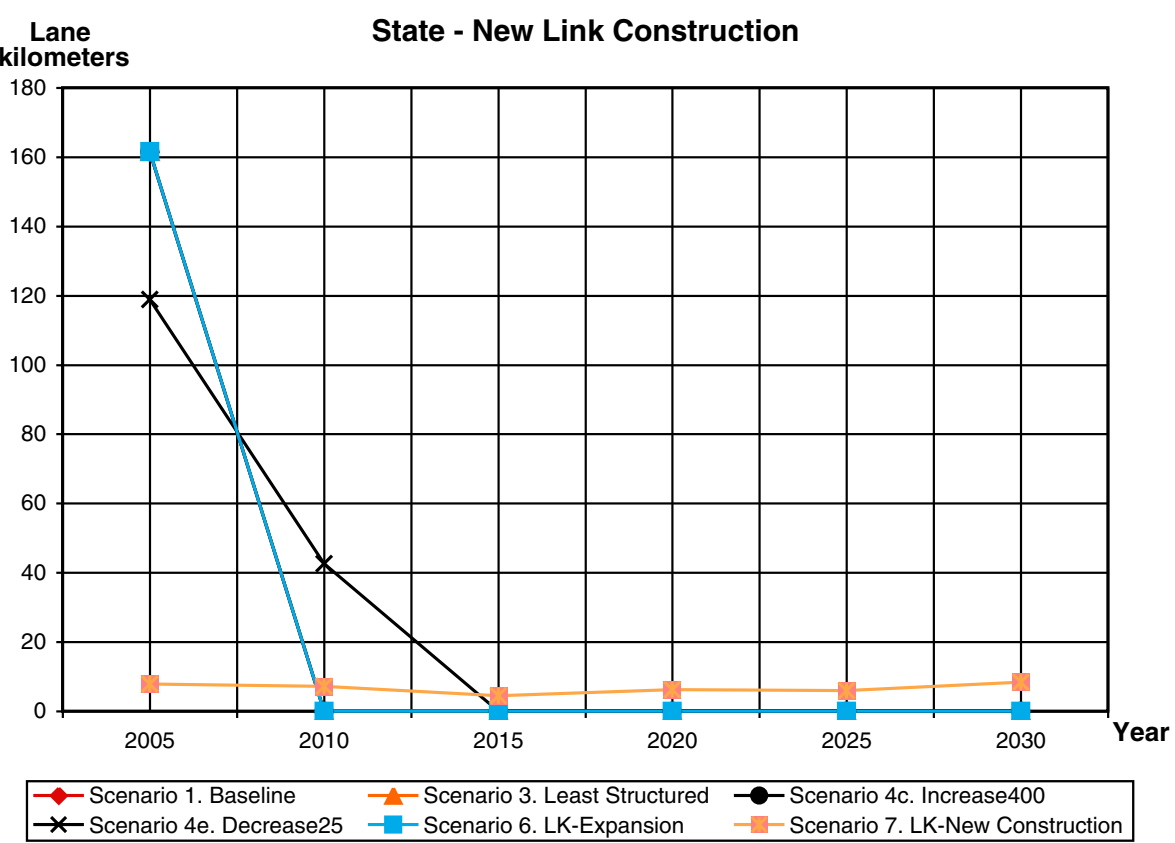

Fig. 4 New construction by the state for different scenarios

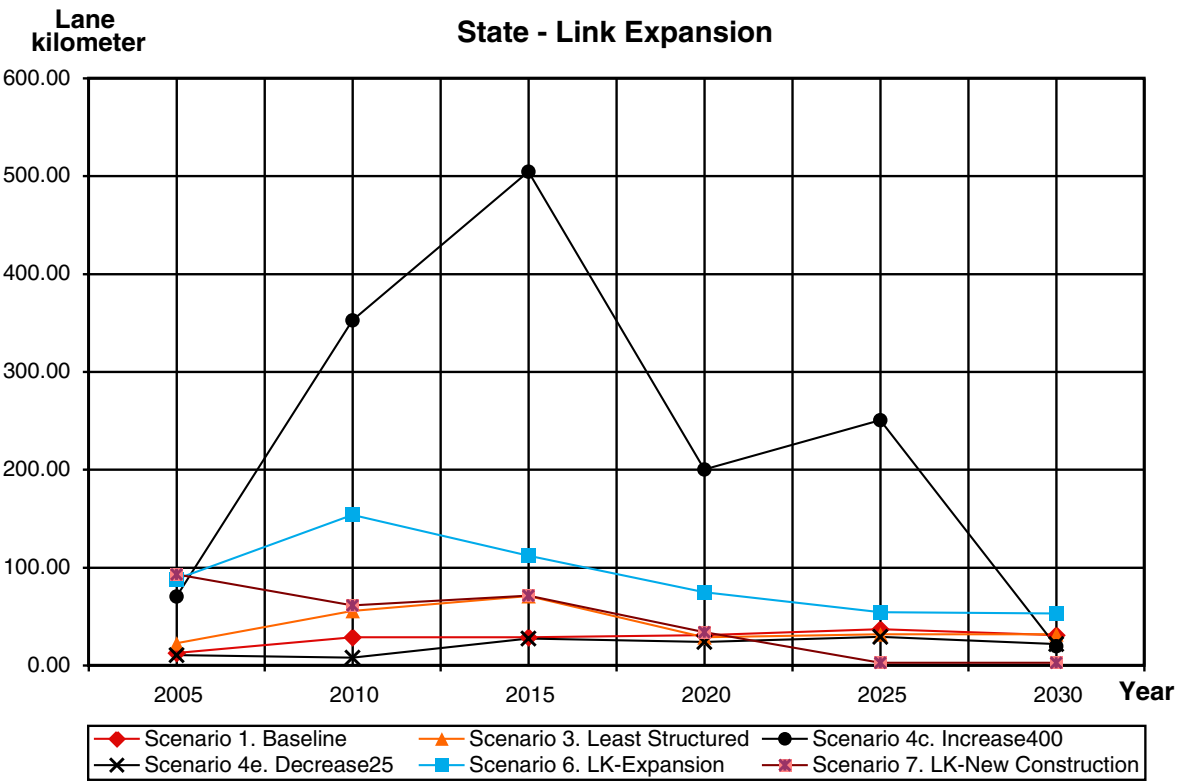

Fig. 5 Link expansion by the State for different scenarios 
plummets for all except Scenario 4e and Scenario 7 because all of the legacy links are built by 2010 (and the choice set of new construction is exhausted). Scenario 4e does not exhaust the new construction opportunities until 2015 because of a decreased budget, while Scenario 7 provides a larger set of potential unbuilt links to choose from. Once new construction opportunities are exhausted, the scenarios reallocate new construction funds to roadway expansion. Expansions are greatest in Scenario 4c which has a $400 \%$ increase in total budget available for construction. The other scenarios are much more similar in total amounts of expansion, though Scenario 6 has more expansions than the others, because it adopts revealed decision rules which take into consideration economy of scale in expansion cost, so that longer roads can get expanded with higher priorities with lower cost rate per lane kilometer (Scenario 7, despite also adopting revealed rules, has fewer expansions because the money for new construction remains with new construction).

Figure 6 shows the predicted expansions in Scenario 1 (the baseline scenario) for the state. The model projects the state will construct continuations of Highways 610 and 212 in the 2005 period. In the 2015 period there will be some expansion on sections of I-35E and on I-494 west of I-35W. Sections of Highway 100, I-94, TH62 and I-494 show some expansion by the 2020 period. There will be some expansions as well on I-35W from south of I-94 to south of Bloomington by the 2030 period. Highway 10 will also have some expansions over time. There will be some other small expansions spread across the region as well. In the 2015 and 2020 periods the demand for new construction is in the northwest part of the metropolitan area.

Under Scenario 6 (Revealed Decision Rules, Restricted New Construction Choice Set), as shown in Fig. 7, there is new construction at the same time as the base scenario suggested. For Scenario 7 (Revealed Decision Rules, Unrestricted New Construction Choice Set), shown in Fig. 8, at the state level there is no clear pattern either for expansion or new construction. It occurs across the region in different years. While Scenario 7 would be investing in fewer than 10 lane kilometers of new projects per period, the investment would be continuous over 25 years, and not end after the set of legacy links was exhausted. By and large, these investments would not occur on the legacy links.

The program calculates a range of MOEs for each simulation period including average trip time, average trip length, vehicle kilometers of travel (VKT), vehicle hours of travel (VHT), and gravity-based accessibility. Montes de Oca (2006) includes the detailed calculation and predicted fluctuations for each of the MOEs. To illustrate the temporal change of MOEs due to road investment, Figures 9 and 10 compare the fluctuations of average trip time and accessibility, respectively, as predicted in the seven scenarios.

In the base scenario, the predicted individual trip time has increased from $15.0 \mathrm{~min}$ in 2005 to $37.8 \mathrm{~min}$ in 2030 . Figure 9 compares individual trip time over years between Scenarios 2-7 against the base scenario. As can be seen, Scenario 4c (with a $400 \%$ budget increase) provides the shortest trip time among all scenarios in 2030. In contrast to all of the other scenarios that 


\section{Baseline Scenario}

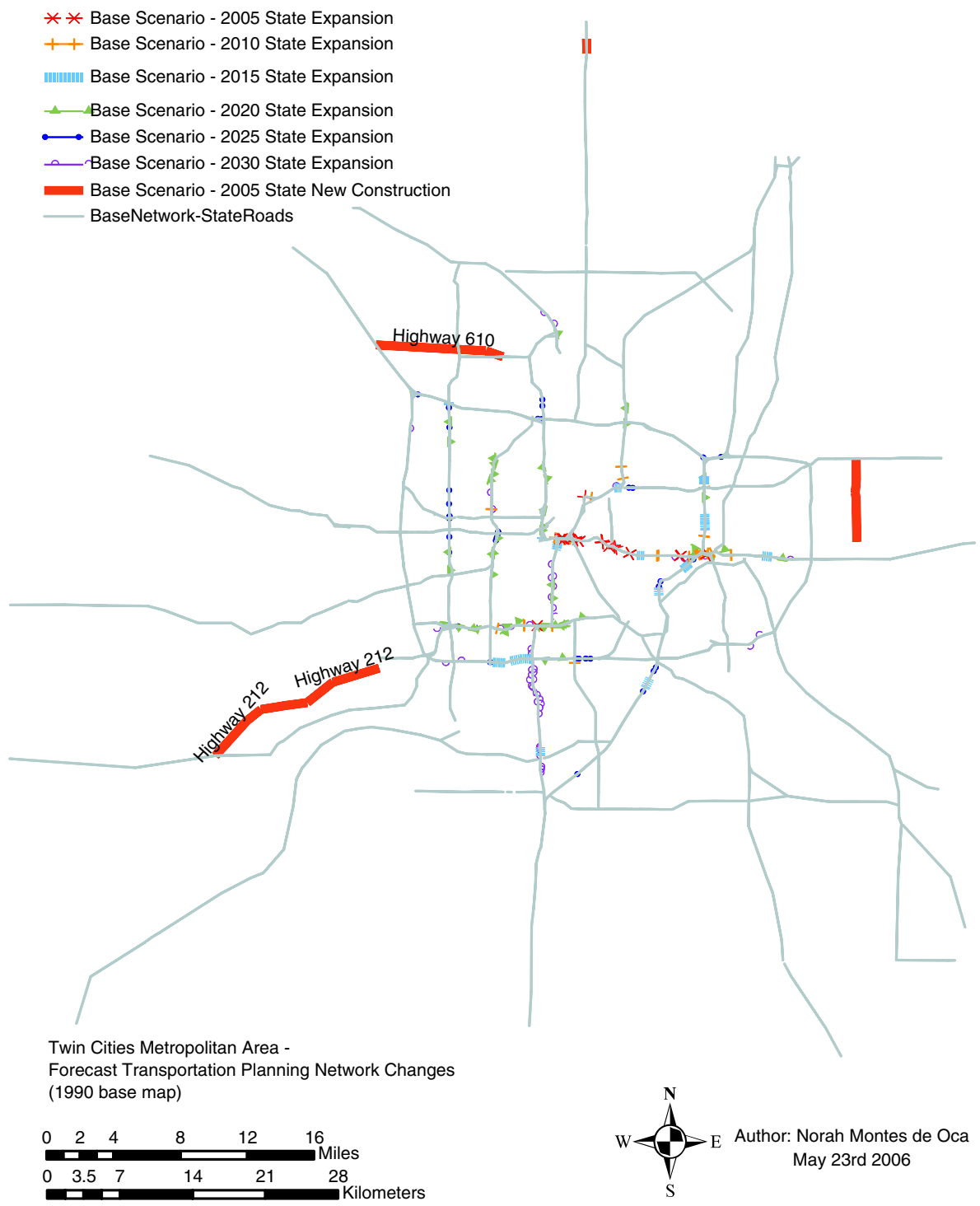

Fig. 6 Scenario 1. Stated rules expansion + new construction + legacy link choice set - state

eventually improve upon the base scenario, Scenario 7 results in a trip time that is about 15 min longer than Scenario 1. While the relative positions of trip times across the scenarios are plausible, all the scenarios predict a steep increase in the trip time over years. This may be exaggerated (if historical changes are any guide) due to a variety of modeling assumptions, most significantly, the land use assumptions, which are not likely reasonable in forecast years, the lack 


\section{LK Expansion Model Scenario}

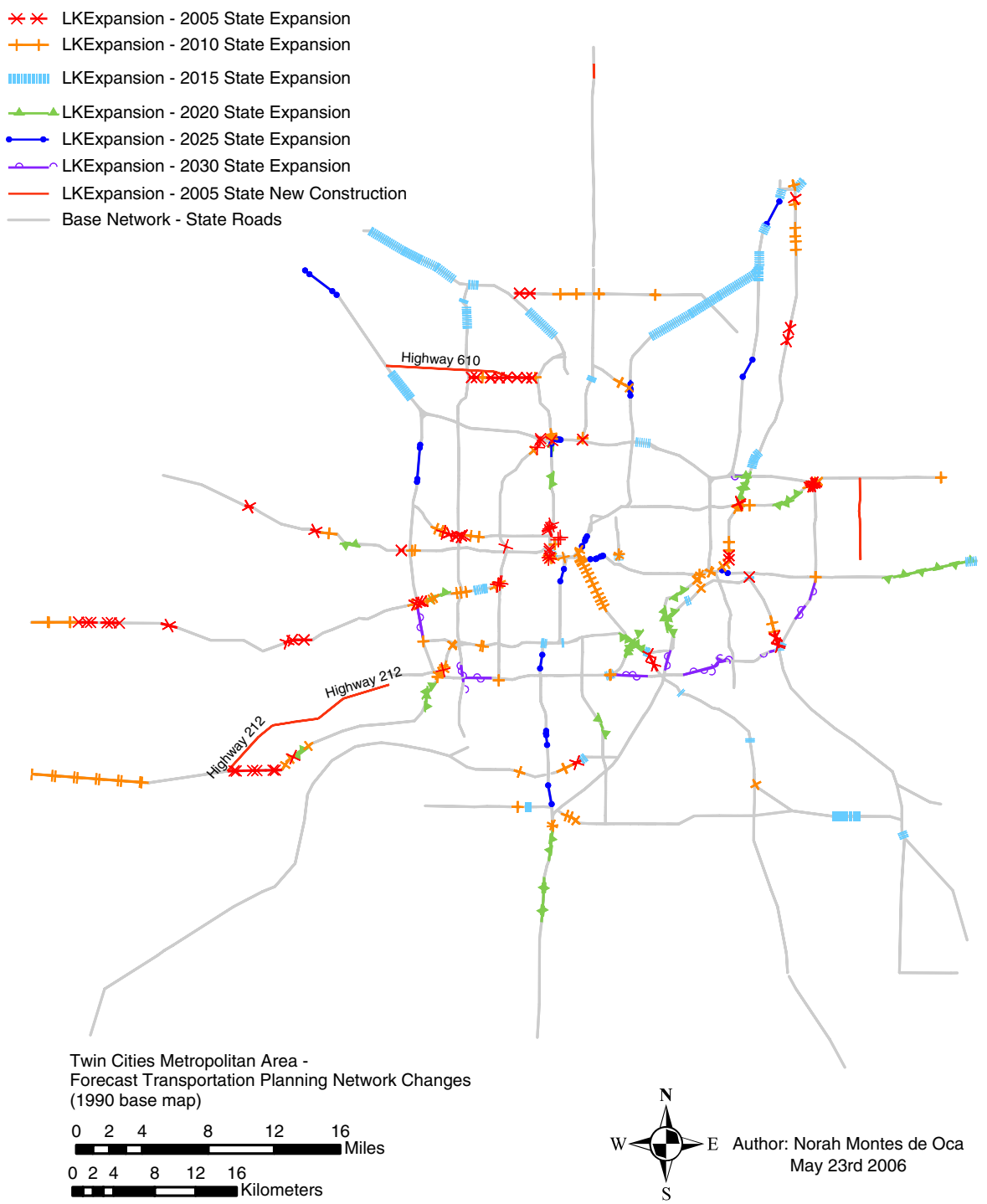

Fig. 7 Scenario 6. Revealed rules expansion + new construction + Legacy link choice set - state

of peak spreading in the model, the relative insensitivity in the gravity-based trip distribution model to changes in travel time, as well as changes in travel demand at external stations, for which we have a very simplistic forecasting procedure due to limited data.

The gravity-based measure of accessibility in this research evaluates the ease of reaching employment opportunities (retails and non-retails) at destinations, 
* * LK Potential - 2005 State Expansion

+ + LK Potential - 2010 State Expansion

\section{LK New Construction Model Scenario}

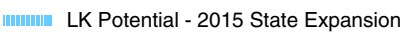

$\triangle$ LK Potential - 2020 State Expansion

. LK Potential - 2025 State Expansion

_ـ LK Potential - 2030 State Expansion

LK Potential - 2005 State New Construction

- LK Potential - 2010 State New Construction

LK Potential - 2020 State New Construction

LK Potential - 2030 State New Construction

Base Network - County Roads

Base Network - State Roads

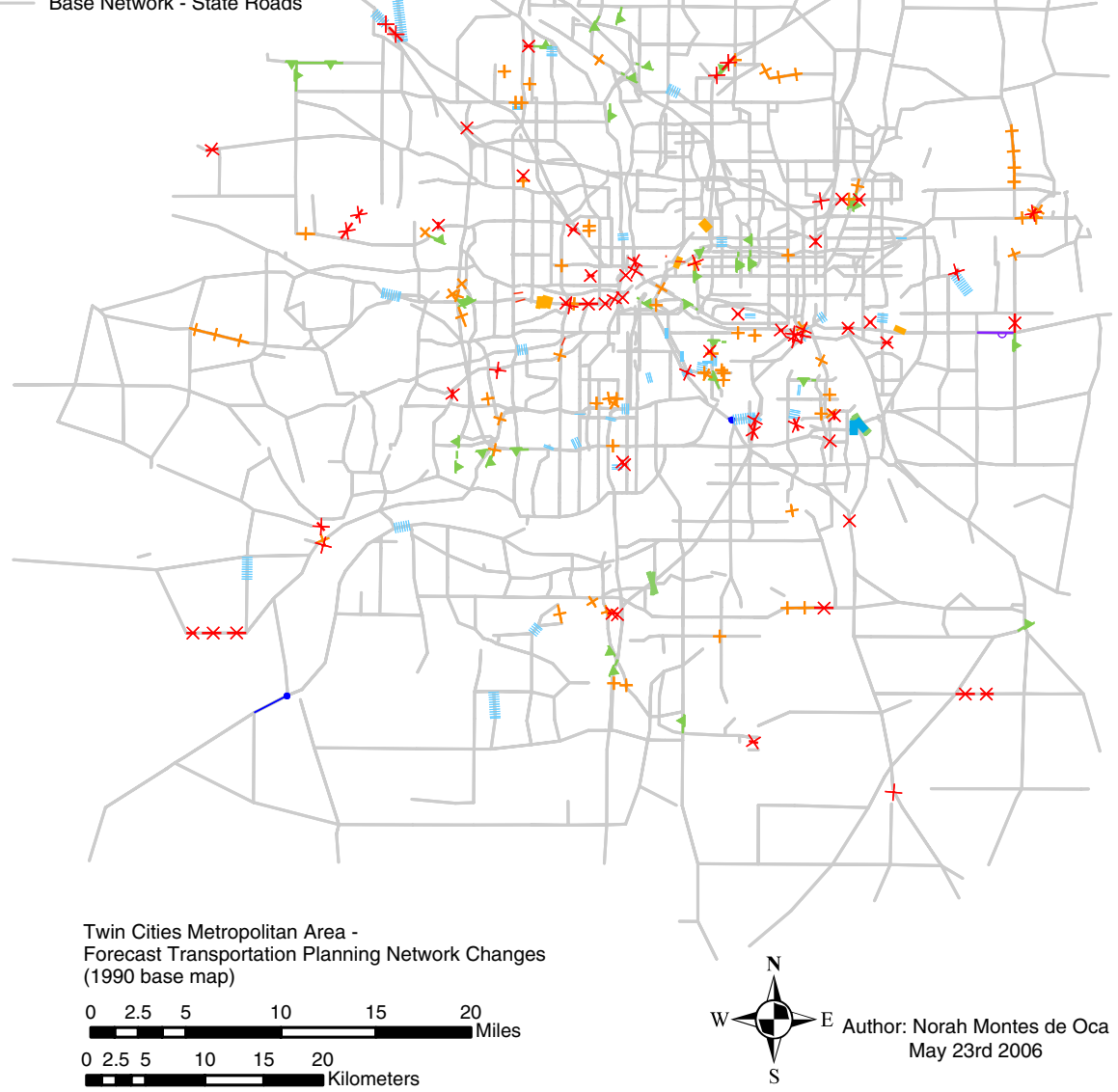

Fig. 8 Scenario 7. Revealed rules expansion + new construction + expanded choice set model state

impeded by the generalized travel time from origins to destinations. The predicted accessibility in the base scenario increases from $1.015 \times 10^{12}$ units in 2005 to $1.500 \times 10^{12}$ in 2030 . The increasing accessibility throughout network growth indicates the benefits travelers in the Twin Cities region have gained due to road investment. Figure 10 compares the measure of accessibility from 


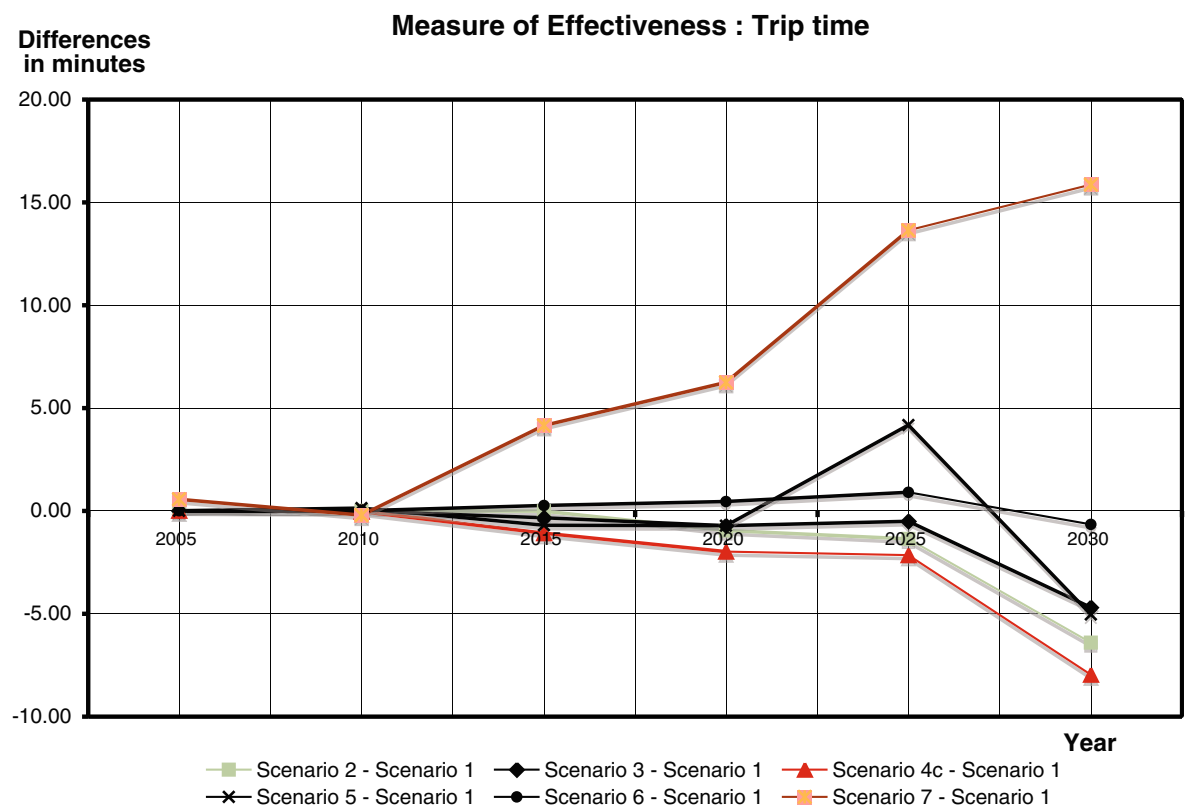

Fig. 9 Measure of effectiveness - trip time

Difference in values

Measure of Effectiveness : Accessibility in Millions

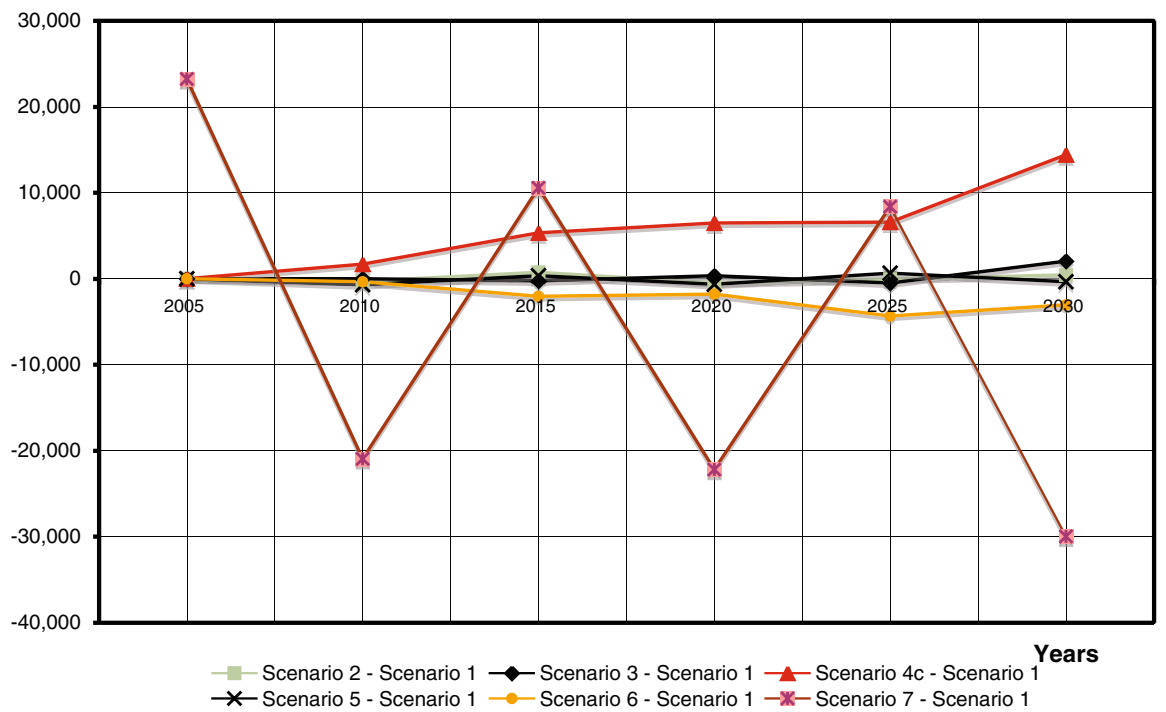

Fig. 10 Measure of effectiveness - accessibility 
Scenarios 2-7 to that in Scenario 1. Scenario 4c again achieve the highest accessibility in 2030 with its increased budget, indicating greater investment can achieve lower travel times and as a result higher accessibility. As compared to changes in total investment, switching specific decision rules or choice sets applied to the network make only marginal changes in network performance. While accessibility has improved substantially in all scenarios, Scenario 6 and Scenario 7 based on revealed decision rules for link expansion result in lower accessibility as compared to the other scenarios, suggesting stated decision rules perform better than revealed rules in terms of improving regional accessibility.

\section{Summary and conclusions}

This research, perhaps for the first time, forecasts changes in transportation networks as a function of empirically derived models, using a travel demand model based on economic theory and observed information. While one must treat with caution any specific results, the exercise is valuable.

This research finds that stated decision rules (in Scenarios 1-5) perform generally better than revealed rules (as adopted by Scenarios 6-7) in terms of improving regional accessibility by investing resources in road infrastructure. The reason may be two-fold. First, stated decisions vary by jurisdictions and may better reflect local investment needs while revealed rules are developed across the whole region and may be less flexible to the heterogeneity of jurisdictions; second, stated rules evaluate investment needs mainly based on present road characteristics, while estimating a statistical model for revealed rules requires a large data set across past years, for which some predicting factors such as level of service and crash rate are difficult to incorporate because of limited availability to historical data.

Another interesting observation is that decision-making with a limited choice set of legacy links for new construction (Scenario 6) appears to achieves a shorter trip time and higher accessibility as compared to that with a larger set of potential new links (Scenario 7). This may be for several reasons. One obvious reason is that more construction (both expansion and new construction) results in Scenario 6. Furthermore, supposing legacy links are strategic links identified in previous transport plans that can effectively complement the current highway network in the Twin Cities, the revealed decision rules didn't identify them among an expanded set of potential links and result in a less contiguous pattern of construction in Scenario 7 than in Scenario 6.

Extensions of this research from a modeling perspective can proceed in several directions. First, the step length between iterations can be reduced from a 5-year model to a 1-year model. One of the reasons for wanting to change from 5-year model to 1-year model is to test an evolutionary model of network growth. In the 1-year model, only a fraction (say 20\%) of all work trips change destinations in a given year. This means that $80 \%$ of trips in previous year would not change, only $20 \%$ of OD demand in that year and additional 
OD demand this year will be redistributed according to the congested travel time calculated at the end of the previous year.

One major criterion we were unable to model was pavement condition, due to a lack of geographically accurate and complete data on the current pavement condition across the regional network. Should this data become available, it would be useful to re-introduce this variable as a factor affecting the timing of investments. Another criterion to be included is safety. A crash rate model needs to be estimated and incorporated in the program to make crashes on roads endogenous. This represents a challenging part of future work as safety plays an important role in decision-making processes of jurisdictions.

Clearly, improvements can be made to the investment models, particularly in the way resources are allocated between new construction and expansion of existing facilities. The available information in those cases is different, resulting in different criteria used to prioritize those types of decisions. Additionally, better models of total revenue, and revenue available for investment, should be aimed for. Assuming a fixed share of total revenue is invested is unlikely, as the network grows and matures, we expect an increasingly large share would be associated with maintenance and preservation, though the data from the past decade do not point to any clear trends.

One of the great benefits of a modeling exercise such as that conducted in this research is not simply the predictions, it is the process, which requires coding decisions into a computer program in a logical way, forces the specifications of all of the assumptions that are often expressed vaguely in typical spoken and written human communication. There are many parts of the decision-making process that are underspecified in written documents, leaving ambiguity and opportunities for special-case politics rather than systematic consideration and evaluation of decisions according to agreed upon principles. While that ambiguity may be intentional, it reduces transparency in the system and opens it up for manipulation.

\section{References}

Besley T, Coate S (2003) Centralized versus decentralized provision of local public roads: a political economy approach. J Public Econ 87:2611-2637

Bureau of Public Roads (1964) Traffic assignment manual. US Dept. of Commerce, Urban Planning Division, Washington, DC

Davis G, Sanderson K (2002) Building our way out of congestion? Highway capacity for the Twin Cities. Technical report, Mn/DOT 2002-01

de Dios Ortuzar J, Willumsen LG (2001) Modeling transport. Wiley, New York

Garrison WL, Marble DF (1962) The structure of transportation networks. Technical report, 62-II:73-88

Kansky K (1969) Structure of transportation networks: relationships between network geometry and regional characteristics. University of Chicago Press, Chicago

Knight B (2001) Endogenous federal grants and crowd-out of state government spending: theory and evidence from the federal highway aid program. Am Econ Rev 92(1):71-92

Levinson D, Karamalaputi R (2003a) Induced supply: a model of highway network expansion at the microscopic level. J Transp Econ Policy 37(3):297-318 
Levinson D, Karamalaputi R (2003b) Predicting the construction of new highway links. J Transp Stat 6(2/3):81-89

Levinson D, Yerra B (2006) Self organization of surface transportation networks. Transp Sci 40(2):179-188

Levinson D, Montes de Oca N, Xie F (2006) Beyond business as usual: Ensuring the network we want is the network we get. Technical report, Mn/DOT 2006-36

Minnesota Department of Natural Resources (2003) Regionally significant ecological areas (RSEA) 2003 assessment results. Technical report, MDNR. http://www.dnr.state.mn.us/rsea/ metro_assessment.html

Minnesota Department of Transportation (2001) Metro division transportation system plan. Technical report, MnDOT

Minnesota Department of Transportation (2005) 2002 freeway volume-crash summary. Technical report, Office of Traffic, Security and Operations. www.dot.state.mn.us/trafficeng/otepubl/ CongestionReport-2004.pdf

Montes de Oca N (2006) Beyond business as usual: ensuring the network we want is the network we get. Master's thesis, University of Minnesota

Montes de Oca N, Levinson D (2006) Network expansion decision-making in the Twin Cities. Transp Res Rec 1981 (Planning and Analysis 2006):1-11

Oates W (1972) Fiscal federalism. Harcourt Brace, New York

Sheffi Y (1985) Urban transportation networks: equilibrium analysis with mathematical programming methods. Prentice-Hall, Englewood Cliffs

Suwansirikul C, Friesz TL, Tobin R (1987) Equilibrium decomposed optimization: a heuristic for the continuous equilibrium network design problem. Transp Sci 21(4):261

Taaffe E, Morrill RL, Gould PR (1963) Transportation expansion in underdeveloped countries: a comparative analysis. Geogr Rev 53(4):503-529

Yang H, Bell MGH (1998) Models and algorithms for road network design: a review and some new developments. Transp Rev 18:257-278

Yerra B, Levinson D (2005) The emergence of hierarchy in transportation networks. Ann Reg Sci 39(3):541-553 